\title{
Possibilidades de interface entre lazer e fenomenologia
}

\author{
Natalia Puke* \\ Nelson Carvalho Marcellino**
}

\begin{abstract}
Resumo: Este trabalho consiste na análise das possibilidades de interfaces entre o método fenomenológico e os estudos do lazer, destacando, sobretudo, as possibilidades de pensar os conteúdos e interesses do lazer em relação aos conceitos de corporeidade e linguagem em Merleau-Ponty.
\end{abstract}

Palavras-chave: Atividades de Lazer. Corpo. Filosofia. Linguagem.

\section{INTRODUÇÃO}

Este trabalho, desenvolvido por meio de pesquisa bibliográfica (SEVERINO, 1993), analisa o processo discursivo (BRUYNE et al., 1977) da fenomenologia no intuito de relacionar alguns de seus conceitos aos conteúdos e experiências provenientes do lazer. Do mesmo, analisamos o uso do método fenomenológico nos recentes estudos do lazer que se autointitulam fenomenológicos. Para tanto, percorremos as principais características do lazer e da fenomenologia para propor um encontro desses dois aspectos.

Observamos que abordar o lazer sob o olhar contemporâneo da filosofia fenomenológica, destacando, sobretudo, a leitura de Merleau-Ponty é valorizar a intencionalidade do sujeito, bem como a vivência de certos conteúdos do lazer como linguagens possíveis para a fruição da estética, no sentido amplo do termo. Desse modo,

\footnotetext{
'Professora de Filosofia. Cooperativa Educacional de Piracicaba, Piracicaba, SP, Brasil. E-mail: napuke@gmail.com

"Curso de Mestrado em Educação Física. Faculdade de Ciências da Saúde. Universidade Metodista de Piracicaba, Piracicaba, SP, Brasil. E-mail: marcelin@supernet.com.br
} 
o que está em questão neste trabalho é a compreensão do homem como "ser-no-mundo", o processo de significação e a presença da corporeidade no uso do tempo de lazer.

\section{A Fenomenologia: de Husserl a Merleau-Ponty}

A fenomenologia é uma corrente filosófica que emerge no final do século XIX, instaurando um novo paradigma epistêmico, cuja abordagem funda, propriamente, a filosofia contemporânea. Isso ocorre porque ela sugere uma radicalidade do pensamento ao propor a superação da oposição entre realismo e idealismo, ou seja, das dicotomias entre sujeito e objeto, corpo e espírito, e homem e mundo, estabelecidas, sobretudo, pelas tendências racionalistas, empiristas e positivistas no decorrer da história do pensamento.

Sobre essa ruptura paradigmática, observamos que, no racionalismo, se privilegia o papel atuante do sujeito que conhece, isto é, a supremacia do cogito em relação à "coisa" apresentada. Isso porque no racionalismo, em destaque, o cartesiano, a substância humana é o pensar, que, por sua vez, garante, por si só, todos os atributos do conhecimento. Em relação ao empirismo, prevalece a determinação do objeto conhecido sobre o sujeito, o que significa que o contributo da "coisa" externa formata a realidade subjetiva. Quanto ao positivismo, a dicotomia pauta-se na crença de um conhecimento científico cada vez mais neutro e objetivo, alheio ao sujeito da ação.

Esse jogo de oposições, que percorre quase toda a história da filosofia, é equilibrado na fenomenologia, pois, em sua perspectiva não há dualismo entre sujeito e objeto, o que significa conceber que o sujeito é, ao mesmo tempo, objeto; e o objeto é, ao mesmo tempo, sujeito. Isso porque o fenomenólogo considera que não há qualquer conhecimento alheio à subjetividade, uma vez que não conhecemos o mundo como um dado bruto, e, sim, revestido de significados.

Acerca desses pressupostos, a fenomenologia desenvolve o conceito de intencionalidade, que infere que a consciência sempre 
tende para um alvo, atribuindo-lhe sentido. Assim, considera-se que não há pura consciência separada do mundo, já que toda consciência é sempre consciência de alguma coisa, o que significa que não existe objeto que não esteja comprometido com a relação com o sujeito que o conhece.

A intencionalidade, portanto, como característica central da consciência, aduz que o mundo que percebo não é o mundo "em-si", mas o modo pelo qual ele aparece "para-mim". Daí a importância da investigação do fenômeno, que nessa leitura deve ser compreendido a partir do grego phainomenon, que etimologicamente significa "o que aparece". Sobre tal questão, devemos nos ater, nessa abordagem, que o fenômeno não implica reduzir a existência à aparência, mas, sim, em "voltar às coisas mesmas" (HUSSERL, 2008, p. 17), isto é, descrever os objetos exatamente como se apresentam à consciência no momento em que emerge o conhecimento. Nesse sentido, a proposição de retorno "à coisa mesma" pretende desvelar o que está latente no fenômeno para, enfim, compreender sua essência como fonte da experiência.

Para Edmund Husserl (1859-1938), fundador do método fenomenológico, "essências" não são instâncias metafísicas e substanciais; são "unidades de ideias de significação, elementos constitutivos do sentido de nossa experiência" (MARCONDES, 1998, p. 258), ou seja, a centralidade dessa análise epistêmica é o movimento da consciência e o processo de significação, focando, sobretudo, a vivência do sujeito em sua imanência.

A proposição "voltar às coisas mesmas" é o ponto de partida do método fenomenológico de Husserl, que se constitui propriamente na concepção de redução eidética ${ }^{1}$, cujo intuito consiste em revelar "o horizonte de potencialidade da coisa considerada, independentemente de sua existência real ou concreta" (MARCONDES, 1998, p. 258). Essa concepção pretende purificar a relação entre sujeito e objeto, isto é, expurgar os dados apriorísticos no processo do conhecer. É desse raciocínio que o autor desenvolve

'Eidética, do grego eidos. Significa forma ou essência (MARCONDES, 1998).

Movimento, Porto Alegre, v. 20, n. 01, p. 307-327, jan/mar de 2014. 
a ideia de époche, que designa o sentido de "suspensão do juízo" (ABBAGNANO, 2007). Em termos específicos, no processo da époche os atributos do conhecimento são colocados "entre parênteses" e o autor da ação coloca-se provisoriamente em um estado desinteressado, desprovido dos preconceitos correspondentes à "tese mundo". O objetivo, aqui, é transpor a "atitude natural" e cotidiana para se chegar ao dado imanente da consciência (MARCONDES, 1998).

No que tange à abordagem metodológica da fenomenologia, o filósofo francês Merleau-Ponty (1908-1961) é fortemente influenciado pela concepção husserliana, mas difere por ampliar o conceito de intencionalidade. Na filosofia de Merleau-Ponty a intencionalidade não é apenas uma característica da consciência, mas um movimento que se desenvolve no âmbito da percepção corpórea e na sua imersão no mundo sensível.

Nessa ótica, o corpo é consciência e um truísmo em todo o processo de constituição do conhecimento, uma vez que é tempo, espaço, fala e motricidade. Assim, o corpo inaugura a existência do ser-no-mundo ${ }^{2}$, é "o veículo do ser no mundo" (MERLEAU-PONTY, 1996, p. 129), um campo de presença permanente do qual não podemos nos distanciar, observar em sua totalidade, ou considerar como um objeto, pois existimos com ele e não sabemos o que é ser sem ele.

Observamos aqui que a filosofia do $\operatorname{cogito}^{3}$ dá lugar para a filosofia do corpo vivido, do mesmo modo que os dualismos são nivelados. O corpo não é caverna, nem tampouco uma mera coisa extensa, distinta do ser do homem ${ }^{4}$. Nessa ótica, Merleau-Ponty

\footnotetext{
${ }^{2}$ Merleau-Ponty apropria-se do conceito "ser-no-mundo" de Martin Heidegger, que diz que o homem é Dasein, isto é, um "ser aí" lançado de forma passiva em um mundo já construído pela cultura e determinações biológicas. Porém, mesmo diante da facticidade da realidade, o "ser-aí" é atuante no mundo em virtude de sua consciência intencional, portanto, é capaz de construir sentido para sua existência. É assim que "ao Dasein é inerente essencialmente: ser-no-mundo" (HEIDEGGER, 1989, p. 13) para construir a estrutura de sua subjetividade a partir de um plano de possibilidades que se inaugura no movimento de projeção de "dentro" para "fora".

${ }^{3}$ Abordagem filosófica que enfatiza a supremacia da razão sobre o corpo.

${ }^{4}$ Referência ao platonismo e racionalismo que consideram o corpo um dado ilusório suscetível ao erro.
}

Movimento, Porto Alegre, v. 20, n. 01, p. 307-327, jan/mar de 2014. 
critica que toda filosofia, ciência ou psicologia que proponha uma realidade heterogênea, ou redução de um dito "oposto" a uma aparência ilusória, comete um engano comum que compromete a descrição filosófica.

Desse modo, seu construto é um radical giro epistêmico, na medida em que o corpo apresenta-se como um locus indubitável na constituição humana, onde todo o processo de significação e conhecimento torna-se possível porque encontra-se como que atado no tecido da estrutura do mundo (FARIA, 1996). Isso enuncia que o homem é participante e atuante íntimo das coisas, e mesmo que o corpo possua um "contorno fronteira", o qual as relações de espaço ordinárias não transpõem, nele se mantêm intimamente todas as dimensões da existência, isto é, a relação constante com o Umwelt ${ }^{5}$.

Por essa razão, o autor afirma que o corpo não está separado do mundo, aliás, ele "é feito da mesma carne [...] ele a reflete, e ambos se imbricam mutuamente" (MERLEAU-PONTY, 1971, p. 225). Há uma interioridade que se propaga de um para outro em uma reversibilidade permanente, o que significa que o "mundo" está todo "dentro" e o "eu" está todo "fora" (MARLEAU-PONTY, 1984). Neste sentido, não é possível demarcar onde começa ou termina o conhecimento, bem como onde está o "eu" e o "outro".

Essa leitura fundamenta-se na observância de que o mundo, antes de ser pensado, é vivido, e o homem, consequentemente, antes de ser consciente, é sensível e visível. Ora, para o "corpo vivido" não existe o ser constituído e o constituinte, ou seja, a racionalidade abstrata que dá nome e forma. Há, em primeiro lugar, um entrelaçado simultâneo e mudo de "um" "com" e "para" o "outro", pois "ter um corpo é, para um ser vivo, juntar-se a um meio definido, confundirse com certos projetos e empenhar-se continuamente neles" (MERLEAU-PONTY, 1996, p. 129).

${ }^{5} \mathrm{Em}$ alemão, significa "ambiente" ou "meio circundante", portanto, o corpo seria o totalizador de movimento, o levantamento de nossa situação espacial no mundo (MERLEAU-PONTY, 2000). 
É por conta desses aspectos que a fenomenologia de MerleauPonty valoriza a vivência subjetiva e a particularidade das experiências, já que "quer se trate do corpo de outro ou de meu próprio corpo, não tenho outro meio de conhecer o corpo senão vivendo-o, quer dizer, retomar por minha conta o drama que o transpassa e confundir-me com ele" (MERLEAU-PONTY, 1996, p. 269).

O corpo concentra toda a nossa potência motora, não simplesmente sob o aspecto do movimento em sua locomoção espacial, mas, principalmente, àquilo que se relaciona com o nosso agir, atuar e transformar o mundo. Desse modo, o corpo aloja um "projeto motor" (Bewegungsentwur), uma "intencionalidade motora", sem os quais a ordem permaneceria letra morta" (MERLEAUPONTY, 1996, p. 159). Neste sentido, conclui-se que é pelo corpo que a humanidade passa a existir na produção da cultura.

No processo da constituição humana, a percepção corpórea inaugura a abertura do "ser" para o mundo e possibilita a projeção do "si" para fora ${ }^{6}$. Essa projeção é a "função pela qual o sujeito do movimento prepara diante de si um espaço livre onde aquilo que não existe naturalmente possa adquirir um semblante de existência" (MERLEAU-PONTY, 1996, p. 60). Por esse viés, a essência da consciência humana é "dar-se um mundo ou mundos, quer dizer, fazer existir diante dela mesma os seus próprios pensamentos enquanto coisas" (MERLEAU-PONTY, 1996, p. 183). Nesse sentido, o movimento de projeção, que é propriamente a intencionalidade, inaugura o processo de criação de sentido na procedência da relação de nossa percepção corpórea com o mundo.

Acerca dessas palavras, observamos que a significação assume grande importância em sua obra, e é por isso que a análise da linguagem acompanha o desenvolvimento de sua filosofia. Isso porque a significação alimenta toda a linguagem, tal como o mundo alimenta o corpo (FARIA, 1996).

${ }^{6}$ Ver nota 4.

Movimento, Porto Alegre, v. 20, n. 01, p. 307-327, jan/mar de 2014. 
Na leitura de Merleau-Ponty há duas formas de linguagem: a "fala falada" que remete à "linguagem sedimentada, constituída por significações correntes e pelas demais formas de expressão de um dado meio sociocultural" (BOCCHI; FURLAN, 2003, p. 446), isto é, ligada à função comunicativa do cotidiano, e a "fala falante", que é a "linguagem em estado nascente, como um ato instituinte e criativo" (BOCCHI; FURLAN, 2003, p. 446), ou seja, é artística, como uma expressão reinventiva.

O autor destaca que a linguagem falada, isto é, a artística, enuncia-se como uma ponte para apreensão do ser, ou mesmo do mundo. Nesse diapasão, o autor considera que, das linguagens do escritor, mediante os signos já elaborados pela linguagem falada, e a do pintor, via expressão icônica emergem o que denomina "enigmas" (FARIA, 1996). Isso porque na linguagem literária inaugura-se a problemática da significação, cuja interpretação sempre supera o significante, que, por sua vez, não cessa de engendrar novas significações. O que o autor constata é que entre significado e significante nunca existe equilíbrio, mas um ultrapassamento de um pelo outro, ou graças ao outro, por meio das atribuições de sentido que são sempre contingentes na medida em que correspondem à vivência de cada sujeito.

Em relação à pintura, o enigma consiste em fazer com que os objetos estejam na tela sob condição expressa de não estarem ali, isto é, de transcenderem a materialidade, de criarem "mundos" e sentidos para o mundo sem a adequação de signos verbais. Para Merleau-Ponty, a linguagem visual, por não necessitar de signos verbais, é a experiência estética mais bruta do real. É por isso que ele escreve que a pintura visa à "gênese secreta e febril das coisas em nosso corpo" (MERLEAU-PONTY, 1984, p. 92), o que vem a revelar o movimento de reversibilidade entre corpo e mundo.

Essas questões são abordadas em suas obras A dúvida de Cézanne e O olho e o espírito. Na leitura de Merleau-Ponty, o pintor emprega seu corpo na obra com seu emaranhado de sensações; empresta-o ao mundo, transformando este último em obra de arte. Desse modo, o corpo está na pintura, não só porque esta necessita 
da vivência sensória do sujeito que a vislumbra, mas, também, porque necessita de técnica ${ }^{7}$ e toda técnica é técnica do corpo que "figura e amplia a estrutura metafísica da nossa carne" (MERLEAU-PONTY, 1984, p. 92).

É por esses aspectos que, por meio do olho, o pintor é comovido pelo impacto do mundo e o restitui ao visível pelas mãos. $\mathrm{O}$ olho comporta-se como um instrumento que se move por si mesmo e como um meio que inventa seus próprios fins. Dessa maneira, o pintor pratica uma espécie de "teoria mágica" da visão, que a desperta e eleva-a a uma potência de delírio, no sentido entusiástico, capaz de estender a posse de todos os aspectos do "ser"8, do não dito, por meio de sua fascinação, que é projetada no quadro (MERLEAUPONTY, 1984).

$\mathrm{Na}$ experiência estética, o pintor, a obra e o mundo estão como enxertados em uma unidade de "ser"; há o rompimento das fronteiras racionalizadas que pretendem controlar o "si mesmo" e a realidade exterior. Nesse sentido, emerge a experiência do movimento de reversibilidade entre homem e mundo, em que é impossível dizer onde finda a natureza e começa o homem ou a expressão. Entre autor e obra, ou espectador e obra, não se sabe quem toca ou quem e tocado, visto que nessa relação de "um" "com" ou "para" o "outro" estabelece-se um entrelaçado mudo que é acolhido na sensibilidade corpórea. Todas as dimensões da existência revelam-se em uma significação silenciosa, que as palavras são incapazes de comportar, pois na arte "o próprio Ser mudo que vem a manifestar seu próprio sentido" (MERLEAU-PONTY, 1984, p. 109).

A arte icônica, no sentido de Merleau-Ponty, por se tratar de uma expressão sem signos e conceitos, configura-se como uma forma expressiva quase natural, muito próxima da experiência pré-reflexiva. Desse modo, a arte não é um simulacro da realidade, nem tampouco

\footnotetext{
"Técnica, do grego Téchne. Designa "saber fazer", "saber construir", "produzir" no sentido de "criar" algo (SANTAELLA, 1994).

${ }^{8} \mathrm{O}$ "ser" em Merleau-Ponty não é absoluto, substancial ou estático, como pretendiam as leituras clássicas e modernas, mas um "ser abismo", "pré-reflexivo" que se manifesta num devir aracional e como um campo de possibilidades no logos do mundo estético.
} 
um artifício para confortar a existência. Pelo contrário, a arte é um grito inarticulado que "desperta na visão ordinária as potências adormecidas, um segredo de preexistência" (MERLEAU-PONTY, 1984, p. 104).

\section{LAZER E FENOMENOLOGIA}

Há alguns trabalhos no âmbito da Educação Física que se desenvolvem seguindo princípios da fenomenologia, efetuados, principalmente, por pesquisadores do Núcleo de Estudos de Fenomenologia em Educação Física da Universidade Federal de São Carlos (NEFEF-UFSCar) e do Departamento de Educação Física da Universidade Estadual de São Paulo (Unesp).

Observamos que, na abordagem desses pesquisadores, privilegia-se a análise da manifestação do lazer a partir do método "fenômeno situado". A aplicação desse método em uma pesquisa de campo preocupa-se com a perspectiva do sujeito que vivencia a atividade do lazer. Nesse sentido, do ponto de vista do pesquisador, esse método equivale à redução fenomenológica epoché de Husserl, discutida anteriormente.

Para os pesquisadores da área, a investigação, pela ótica da fenomenologia, "visa às operações da consciência do colaborador entrevistado, e não teorias, a prioris ou pré-conceitos do pesquisador" (GONÇALVES JUNIOR; LEMOS; RODRIGUES, 2010, p. 86). Valendo-se da experiência subjetiva do sujeito, a abordagem fenomenológica do lazer considera a representatividade plural de toda atividade ou atitude, o que significa pautar-se em uma pesquisa qualitativa da singularidade, e não em estatísticas que pretendem a generalização dos dados amostrados. Desse modo, intui-se o aprofundamento do mundo vivido pelo autor da ação, observando sua intencionalidade e os significados atribuídos na experiência do lazer.

Acerca dessas questões, a análise do "fenômeno situado" constitui-se em dois momentos: o da análise ideográfica e o da análise 
nomotética. A primeira "refere-se ao emprego de ideogramas ou representações por meios de símbolos" (GONÇALVES JUNIOR; LEMOS; RODRIGUES, 2010, p. 86) para penetrar no campo de significações dos indivíduos. Após a leitura das unidades de significações selecionadas, recorre-se à análise nomotética, "a qual indica um movimento de passagem do nível individual para o geral da manifestação do fenômeno" (GONÇALVES JUNIOR; LEMOS; RODRIGUES, 2010, p.87).

A proposta dos autores busca a essência do fenômeno, isto é, aquilo que se apresenta na consciência do entrevistado, para apreender, sem a prioris os dados brutos da experiência que cada sujeito tem do lazer. Contudo, um olhar mais criterioso permite-nos afirmar que esta proposta não exclui em nenhum momento das análises - ideográfica e nomotética -, a subjetividade do próprio pesquisador, que interpreta os símbolos e organiza os significados das respostas coletadas. Ora, observamos que um estudioso da fenomenologia considera que não há qualquer conhecimento alheio à subjetividade, nem mesmo uma ciência neutra, uma vez que não conhecemos o mundo como um dado bruto e, sim, revestido de significados. Desse modo, mesmo propondo o método da epoché, no processo do desenvolvimento da pesquisa, entre entrevistado e entrevistador, há também o entrelaçado de intencionalidades de ambos os lados que se misturam na produção do resultado.

No que tange à discussão do conceito de lazer pela perspectiva da fenomenologia, Lima, Ferreira e Fragoso (2005) apontam outras contribuições. Segundo os autores há necessidade de superar as dicotomias entre trabalho e lazer, na medida em que se prevalecem sobre esses temas, leituras que se configuram sempre em oposições interpretativas. Sobre o trabalho, é recorrente estabelecerem-se as relações entre explorados e exploradores; sobre o lazer, os derivativos de alienação e libertação. Desse modo, esses autores acreditam que esse jogo dual restringe-se nos polos de desprazer e prazer, o que significa desconsiderar as múltiplas representatividades das experiências. Nesse sentido, os pesquisadores observam que essa visão dialética, oriunda do materialismo-histórico, desconsidera a 
complexidade dos fenômenos cotidianos e as maneiras diferenciadas pelas quais os indivíduos experimentam tanto a vivência do trabalho quanto a do lazer.

Um aspecto interessante, apontado na análise de Lima, Ferreira e Fragoso (2005), é a tentativa de desconstruir a compreensão que considera que o desempregado não tem a possibilidade de vivenciar o lazer. Para Marcellino (2010), por exemplo, o lazer constitui-se na tensão entre tempo e trabalho; portanto, não tendo trabalho, o tempo gerado pelo desemprego não é um tempo de lazer, mas um tempo ocioso ou desocupado. Contudo, na observação de Lima, Ferreira e Fragoso (2005), é possível pensar que "as pessoas desempregadas apresentam, como lazer, o procurar trabalho" (LIMA; FERREIRA; FRAGOSO, 2004, p. 13).

Observando as considerações de Lima, Ferreira e Fragoso (2005), pode-se pensar que, ao excluir as delimitações do tempo de trabalho e tempo de lazer, este último sublima-se e tende a tornar-se mais um espaço e tempo onde prevalece a supremacia dos imperativos de uma sociedade do trabalho. Sabemos que, embora haja divergências sobre a recorrência histórica do lazer, grande parte dos pensadores sobre a temática concorda que o advento da sociedade urbana industrial transformou as relações entre o homem e trabalho, e, principalmente, entre homem e tempo, em virtude da demarcação das horas de labutação nas fábricas. Apesar de as lutas trabalhistas possibilitarem melhores condições e direitos para os trabalhadores, observa-se que os aparatos tecnológicos, tais como celulares, palmtops e e-mails fizeram com que as horas de trabalho fossem estendidas para a casa. Percebe-se, assim, que a jornada de trabalho na era cibercultural tem aumentado nos últimos anos, invadindo a propriedade do nosso tempo, misturando-se com a privacidade de nossos hábitos. Sobre essa questão, Adauto Novaes (2011) destaca que "permanece irrealizada a utopia da libertação do homem pelas máquinas: nunca se trabalhou tanto, e o tempo livre jamais esteve tão fora da pauta" (NOVAES, 2011).

Acerca desses aspectos, questionamo-nos sobre o uso da análise fenomenológica na ruptura das dicotomias entre trabalho e lazer, 
uma vez que relacionar a privacidade do tempo "lícito" às obrigações socioeconômicas reafirma ainda mais a cultura da produtividade. Daí a importância do esclarecimento sobre o que é lazer, mesmo porque os discursos da sociedade da produção e consumo tendem a vender ideários que instituem sobre as representatividades do lazer valores perniciosos que diluem os significados salutares que podem emergir no tempo da sua vivência.

Nossa crítica não está pautada na necessidade de delimitar metodicamente o tempo de lazer e de trabalho, mesmo porque, sabemos que só há lazer porque há trabalho. A dialética não propõe tão somente oposição; é preciso compreender que o movimento de tensão é de complementaridade, logo, uma relação de interdependência.

Diante dessas problemáticas, reconhecemos a complexidade do uso do método fenomenológico nos estudos do lazer. Por isso, a seguir, não vamos nos pautar na aplicação do método, mas em uma livre interpretação da noção de intencionalidade e corpo em MerleauPonty com aquilo que se denominam interesses e conteúdos culturais do lazer.

Segundo o sociólogo Marcellino (2007), o lazer pode ser compreendido como o "tempo disponível" para além do trabalho e das obrigações em que o indivíduo encontra a possibilidade de desenvolver atividades, bem como posicionar sua atitude para o usufruto do ócio. Nesse sentido, o lazer é um complexo de vivências possível de se manifestar em uma diversidade de conteúdos culturais que se definem pelos interesses físico-esportivos (exercícios/ movimento), sociais (festas/associações), artísticos (apreciação ou produção estética), manuais (artesanato e bricolage), intelectuais (leitura/palestras) e turísticos (passeios/viagens). Contudo, embora haja essa definição categórica, deve-se atentar para o sentido de que "os vários interesses que as aspirações pela prática do lazer envolvem formam um todo interligado e não constituído por partes estanques" (MARCELLINO, 2006, p. 17).

A partir das concepções de Dumazedier (1980), Marcellino (2006) discorre que é exatamente na "distinção entre o que se busca 
de forma preponderante no desenvolvimento de várias atividades que se abre a possibilidade para a classificação dos seus conteúdos" (MARCELLINO, 2006, p. 17). Nesse sentido, a distinção entre os conteúdos do lazer "só pode ser estabelecida em termos de predominância, representando escolhas subjetivas, o que evidencia uma das características das atividades de lazer - a opção" (MARCELLINO, 2006, p. 17).

Acerca dessas questões, pode-se relacionar a análise dos interesses e conteúdos culturais do lazer ao conceito de intencionalidade em Merleau-Ponty. Considerando que a intencionalidade é propriamente o movimento da consciência na atribuição de sentido para a "coisa" apresentada, ela consiste, portanto, no tender a um alvo, atualizando-se no "eu posso" (MERLEAUPONTY, 1996). Assim, o "eu posso" liga-se ao interesse do sujeito, isto é, à intencionalidade daquilo que se busca na experiência do lazer.

Observamos que, em Merleau-Ponty, todas as instâncias do conhecimento estruturam-se na vivência do sujeito na relação com o mundo no movimento de contingência. Por estes aspectos, podemos propor que, mesmo que o conteúdo do lazer seja o mesmo escolhido por diversos sujeitos, a experiência vivida por eles será diversificada na medida em que se configura na historicidade de cada um, ou seja, naquilo que tende à intencionalidade da busca de sentido, pois cabe considerar que "a realização de qualquer atividade de lazer envolve a satisfação de aspirações dos seus praticantes" (MARCELLINO, 2006, p. 17). Diante disso, por interesses "deve-se entender o conhecimento que está enraizado na sensibilidade, na cultura vivida" (DUMAZEDIER, 1980, p. 110), sem desconsiderar, também, que a "escolha, a opção, está diretamente ligada ao conhecimento das alternativas que o lazer oferece" (MARCELLINO, 2006, p. 17).

Neste ponto da discussão, cabe um olhar culturalista sobre as atividades, experiências e políticas relativas ao lazer, pois se percebe que estão em questão as vivências dos diversos sujeitos sociais. Isso significa que, embora os conteúdos do lazer possam ser categorizados, o que definirá a relação com o lazer é a motivação do 
sujeito da ação, se bem quiser sua intencionalidade. Nesse sentido, seguindo a leitura de Merleau-Ponty, pode-se interpretar que o lazer apresenta-se como um campo de possibilidades que toma forma mediante a significação do sujeito. Daí, enquanto significação, o lazer pode ser apreendido como uma linguagem expressa pelo corpo no "tempo disponível". Nessa linha de interpretação, o lazer pode incorporar tanto a "fala falada", que designa as significações recorrentes num dado meio sociocultural, quanto a "fala falante", que se refere ao ato criativo, como se pode constatar na expressão artística.

Exemplificando pormenores, nessa relação atribuída entre o lazer e a linguagem, compreende-se que o lazer, como "fala falada", recorre a determinações de valores já instituídos pela sociedade, destacando, principalmente, os referenciais da cultura do trabalho e mercado - ou seja, o lazer funcionalista enquanto compensação física ou produto a ser consumido. Já o lazer como "fala falante" segue como um ato instituinte da experiência estética, podendo, portanto, vincular-se ao conteúdo artístico do lazer, tanto pela apreciação quanto pela criação. Tal como discorremos em Merleau-Ponty, a linguagem artística apresenta-se como uma ponte para a experiência préreflexiva, donde enaltece a relação do "ser". Cabe lembrar que o "ser" de Merleau-Ponty não é algo metafísico ou abstrato, mas aquilo que se revela na linguagem no âmbito das significações, no uso do corpo enquanto expressão.

Na leitura de Merleau-Ponty, o corpo é tempo, espaço, fala e motricidade. Este último aspecto, ou seja, a motricidade, possibilitanos estabelecer uma relação com os interesses físico-esportivos do lazer pelo viés da contemplação estética. Segundo Marcellino (2006, p. 17), embora não seja de modo específico, "pode-se argumentar que o domínio do movimento e do exercício físico também é um campo para a manifestação estética". Essa afirmação permite-nos pensar a manifestação estética do movimento físico-esportivo em duas perspectivas interdependentes: pode-se analisar esteticamente o trabalho corporal que enfatiza a forma da performance atlética no domínio dos movimentos e no desenvolvimento da musculatura e 
força, e, também, a partir do conteúdo da experiência vivida pelo autor da atividade ou do espectador.

Essas duas perspectivas em referência vinculam-se, de alguma maneira, ao sentido etimológico do termo estética, que, advindo do grego aisthesis, designa "faculdade de sentir" e "compreensão pelos sentidos" (SANTAELLA, 1994). Isso porque predominam, em ambas as perspectivas, os dados sensoriais, que por sua vez são propriamente atributos corpóreos. Na performance atlética encontramos a apreciação da visão, principalmente o fascínio que liga a noção de belo, compreendida tradicionalmente, a partir da ótica grega, nas qualidades formais da harmonia, simetria e equilíbrio. A segunda perspectiva privilegia o conteúdo da experiência, considerando, portanto, o sentimento vivido, as emoções que emergem no corpo do autor da atividade, ou no espectador, como experiências eufóricas e extáticas.

No que se refere a essas questões, o teórico literário Hans Ulrich Gumbrecht (2007), baseando-se ontologicamente no estudioso de fenomenologia Martin Heidegger, desenvolve uma análise da experiência estética no esporte, tanto do ponto de vista do atleta quanto do espectador, a partir do conceito "perder-se numa intensidade focada"'.

Desse conceito o autor caracteriza a experiência do esporte em três dimensões. A primeira está relacionada ao contentamento do espectador ao assistir um jogo ou uma performance atlética de alto rendimento. $\mathrm{O}$ momento vivido passa a ser único na medida em que se isola dos demais aspectos que compõem a realidade. Utilizando um exemplo, observamos que se torna evidente, na cultura brasileira, o culto ao futebol e a euforia vivenciada pelos torcedores durante as finais dos campeonatos. O espírito de festa toma conta do cotidiano

\footnotetext{
9Gumbrecht desenvolve o conceito "perdido numa intensidade focada" a partir da declaração de Pablo Morales, um nadador três vezes medalha de ouro em Jogos Olímpicos. Em 1988, Morales declarou que decidiu voltar a disputar os Jogos Olímpicos quando assistiu ao revezamento do atletismo em que a corredora Evelyn Ashfort, última colocada na prova, ultrapassou as demais competidoras e ganhou o ouro para os EUA. Morales relatou que a atleta estava "perdida numa intensidade focada", e este acontecimento produziu um efeito imediato em seu corpo, enquanto espectador, tendo até que se retirar da sala. Após refletir sobre essa sensação que o tomara subitamente, ele afirmou que estava "perdido numa intensidade focada" (GUMBRECHT, 2007).
} 
desses sujeitos torcedores que se voltam atentamente para os eventos futebolísticos como que desprendidos das demais preocupações sociais. Nesse sentido, "'perder-se' converge com a definição do sagrado como um domínio cujo fascínio reside no fato de ele estar separado do mundo cotidiano" (GUMBRECHT, 2007, p. 12). A segunda característica pertence ao âmbito do encantamento, como uma espécie de epifania, cuja focalização nos movimentos dos corpos provoca a sensação de expectativa, como se o espectador fosse partícipe do momento de uma determinada jogada ou lance. A terceira característica desdobra a sensação de expectativa em um êxtase coletivo, em que as emoções de prazer ou desespero são suscitadas pelas intensidades dos acontecimentos, por exemplo, gol, pênalti ou vitória.

A leitura de Gumbrecht (2007) compreende o conceito "perderse numa intensidade focada" no âmbito de uma manifestação irracional, cujas características são similares às epifanias, no sentido de apresentarem um desprendimento do real, tal como uma manifestação religiosa. Nesse sentido, é como se o esporte provocasse uma epifania secular, cujo culto configura-se na consagração do espetáculo dos movimentos corpóreos dos atletas, e não na intuição de um "ente" transcendente.

O autor busca sua fundamentação conceitual na representação da cultura olímpica grega. Salvo os diacronismos historiográficos, podem-se estabelecer algumas relações simbólicas entre as competições atléticas gregas e os eventos de grande porte da nossa época. Os atletas gregos eram considerados semideuses (não tão diferente da representação simbólica dos ídolos atuais); a mentalidade mítica do período acreditava que, nos grandes momentos olímpicos, os deuses tornavam-se presentes no espaço e nos corpos dos atletas pelo que se denominava agon, isto é, na luta e competição. Assim sendo, "assistir às competições dos atletas proporcionava aos seus espectadores a certeza de estar perto dos deuses" (GUMBRECHT, 2007, p. 13). Tal como em uma experiência religiosa, os espectadores permitiam a vazão das emoções e se sentiam parte de um corpo comum, o que não é tão diferente dos eventos atuais, se tomarmos como referência as torcidas organizadas, ou não. 
Essa sensação comunal que se impõe no âmbito dos atributos sensórios - visão, tato, grito e audição - constrói a experiência de pertencimento, como se o sujeito estivesse na "coisa" que assiste e fizesse parte do todo que é o espetáculo. Eis aqui, propriamente, a relação de reversibilidade entre homem e mundo proposta por Merleau-Ponty. Embora não encontremos em seus escritos exemplos sobre a experiência do corpo nas atividades físico-esportivas, cabe aqui a referência, em diálogo com seu construto sobre a experiência estética na pintura. Observamos que, na experiência visual da arte, o sujeito e a obra configuram-se como enxertados em uma unidade de "ser", em um movimento de reversibilidade como que duas mãos atadas, pois não sabemos quem toca ou quem é tocado.

Do mesmo modo, a relação entre a visão do espectador e a motricidade do corpo do atleta, tal como uma obra de arte, apresenta a latência da experiência estética que se desenvolve na percepção de pertencimento, de uma natureza essencial do acontecimento fenomênico. Isso porque o sentido e a significação que emergem nas reações dos sujeitos partícipes do acontecimento não possuem demarcações conceituais, mas pulsam simplesmente pelo acolhimento da sensibilidade corpórea, aproximando-se, assim, da proposta da pré-reflexão presente na leitura de Merleau-Ponty.

\section{Considerações finaIS}

Observamos que o uso do método fenomenológico nos estudos recentemente produzidos sobre o lazer apresenta algumas contradições analíticas naquilo que se refere à neutralidade do pesquisador e na dicotomia entre trabalho e lazer. Contudo, destacamos também que nessa abordagem insere-se a compreensão da realidade em termos da perspectiva e significação do sujeito. Neste âmbito, interessou, nessa discussão, pensar o humano como "ser-no-mundo", irremediavelmente partícipe e atuante da realidademundo-experiência pela linguagem e pela valorização do corpo no processo do conhecer. Concluiu-se, portanto, que, ao falar de lazer pela ótica da fenomenologia, a questão do "tempo disponível" configura-se nos aspectos da intencionalidade do sujeito em relação 
aos conteúdos do lazer, destacando, assim, a relação da corporeidade em Merleau-Ponty com a fruição das atividades físico-esportivas como experiências análogas aos conteúdos estéticos. 
Possibilities of interfaces between leisure and phenomenology

Abstract: This work is an analysis of the possibilities of interfaces between the phenomenological method and leisure studies, highlighting in particular the possibilities of reflecting on the contents and interests of leisure in relation to the concepts of embodiment and language in Merleau-Ponty.

Keywords: Leisure activities. Body. Philosophy. Language.

\section{Posibilidades de las interfaces entre el ocio y la fenomenología \\ Resumen: Este trabajo es el análisis de las posibilidades de las interfaces entre el método fenomenológico y los estudios de ocio, destacando en particular la posibilidad de reflexionar sobre los contenidos y intereses de ocio en relación con los conceptos de corporalidad y lenguaje en Merleau- Ponty. \\ Palabras clave: Actividades de ocio. Cuerpo. Filosofía. Lenguaje.}

\section{REFERÊNCIAS}

ABBAGNANO, N. Dicionário de filosofia. São Paulo: Martins Fontes, 2007.

BRUYNE, P. et. al. Dinâmica da pesquisa em Ciências Sociais. Rio de Janeiro: Francisco Alves, 1977.

BOCCHI, J. C; FURLAN, R. O corpo como expressão e linguagem em MerleauPonty. Estudos de Psicologia, Natal - RN, v.8, n. 3, p. 445-450, 2003.

DUMAZEDIER, J. Valores e conteúdos culturais do lazer. São Paulo: Sesc, 1980. 
FARIA, N. J. Corporeidade. In: FARIA, N. J. A tragédia da consciência. Piracicaba: Unimep, 1996. p. $55-68$.

GUMBRECHT, H. U. Perdido numa intensidade focada: esporte e estratégias de reencantamento. Revista Aletria, Belo Horizonte, v. 15, p. 11-19, jan./jun. 2007. Disponível em: <http://www.letras.ufmg.br/poslit/08_publicacoes_txt/ale_15/ ale15_hug.pdf>. Acesso em: 20 jun. 2012.

GONÇALVES JUNIOR, L.; LEMOS, R. M.; RODRIGUES, C. Teorias do Lazer: Contribuições da fenomenologia. In: PIMENTEL, Giuliano G. A. (Org.). Teorias do Lazer. Maringá, Eduem, 2010. p. 73 - 102.

HUSSERL, E. A crise da humanidade europeia e a filosofia. Porto Alegre: EDIPUCRS, 2008.

HEIDEGGER, M. Ser e tempo. Petrópolis: Vozes, 1989.

LIMA, L. A. N.; FERREIRA, L. F. S.; FRAGOSO, R. S. Pesquisas em fenomenologia compreendem o lazer, o ócio e o trabalho. Revista Teoria e Prática da Educação, Maringá, v. 8, n. 2, p. 25-41, 2005. Disponível em: <http://pt.scribd.com/doc/33126105/ Pesquisas-em-fenomenologia-compreendem-o-lazer-o-ocio-e-o-trabalho>. Acesso em: 17 jan. 12.

MARCONDES, D. Iniciação à história da filosofia: dos pré-socráticos a Wittgenstein. Rio de Janeiro: Jorge Zahar, 1998.

MARCELLINO, N. C. Estudos do lazer: uma introdução. Campinas: Autores Associados, 2006.

MARCELLINO, N. C.. Lazer e qualidade de vida. In: MOREIRA, W. M. (Org.). Qualidade de vida. São Paulo: Papirus, 2007.

MARCELLINO, N. C.. Lazer e educação. Campinas: Papirus, 2010.

MERLEAU-PONTY, M. A estrutura do comportamento. São Paulo: Martins Fontes, 1971.

MERLEAU-PONTY, M.. O olho e o Espírito. 2. ed.. São Paulo: Abril Cultural, 1984. (Coleção Os Pensadores).

MERLEAU-PONTY, M.. Fenomenologia da percepção. São Paulo: Martins Fontes, 1996.

MERLEAU-PONTY, M.. A natureza. São Paulo: Martins Fontes, 2000.

NOVAES, A. Apologia da preguiça: sequestro do nosso tempo pelo trabalho. In: Folha de S. Paulo, São Paulo, 24 jul. 2011. Caderno llustríssima. Disponível em: http://www1.folha.uol.com.br/fsp/ilustrissima/il2407201105.htm. Acesso em: 20 jun. 2012. 
PIMENTEL, G. G. A (Org.). Teorias do lazer. Maringá: Eduem, 2010.

SEVERINO, A. J. Metodologia do trabalho científico. São Paulo: Cortez, 1993.

SANTAELlA, L. Estética de Platão a Pierce. São Paulo: Experimento, 1994.

Endereço para correspondência:

Natalia Puke

Rua Santo André, no 40 - Apto 43, Jd. Nova América, 13417-655

Piracicaba,SP, Brasil.

Recebido em: 04.06.2013

Aprovado em: 18.08.2013

Vovimento, Porto Alegre, v. 20, n. 01, p. 307-327, jan/mar de 2014. 